\title{
GOOD GOVERNANCE E O CONSELHO NACIONAL DE JUSTIÇA
}

\author{
Antonio César Bochenek, Vinicius Dalazoana e Vinicius Rafael Rissetti
}

GOOD GOVERNANCE AND THE NATIONAL JUSTICE COUNCIL

\section{RESUMO}

OS SISTEMAS JUDICIAIS, NO BRASIL E EM TODO O MUNDO, ESTÃO PASSANDO POR GRANDES MODIFICAÇÕES NAS ÚLTIMAS DÉCADAS. No BRASIL, DE MOdO ESPECIAL APÓS A CONSTITUIÇÃO FEDERAL DE 1988, VERIFICA-SE UM IMPORTANTE AUMENTO DA JUDICIALIZAÇÃO DAS RELAÇÕES SOCIAIS, DA POLÍTICA E, CONSEQUENTEMENTE, DA IMPORTÂNCIA DA ADMINISTRAÇÃO DA JUSTIÇA. AlÉM DISSO, A FUNÇÃO JUdICIAL TEM HOJE UMA RELEVANTE RELAÇÃO COM AS FUNÇÕES ADMINISTRATIVAS DOS TRIBUNAIS. ASSIM, UMA SATISFATÓRIA PRESTAÇÃO JURISDICIONAL REQUER TAMBÉM BOAS PRÁTICAS ADMINISTRATIVAS. NESSE SENTIDO, AUMENTA PROGRESSIVAMENTE O NÚMERO DE ESTUDOS SOBRE CONCEITOS E TÉCNICAS DE GOOD GOVERNANCE NOS ASSUNTOS PÚBlicos. Neste ARTIgO, SUSTENTA-SE QUE A NOVA COMPREENSÃO DO MODELO DE JUSTIÇA NECESSITA DA IMPLEMENTACCÃO DE TÉCNICAS E PRÁTICAS DE GOOD GOVERNANCE NOS tRIBUNAIS, CONDUZIDAS PELO CONSELHO NACIONAL DE JUSTIÇA, RELACIONADAS PRINCIPALMENTE ÀS IDEIAS DE TRANSPARÊNCIA, PARTICIPAÇÃO, EFICÁCIA, EFICIÊNCIA E COERÊNCIA.

\section{PALAVRAS-CHAVE}

CONSElho Nacional de Justiça; funções da Justiça; ADMINISTRAÇÃO DA JUSTIÇA; GOOD GOVERNANCE; PRINCÍPIOS.

\section{ABSTRACT}

THE JUDICIAL SYSTEMS, IN BRAZIL AND IN THE WHOLE WORLD, ARE PASSING THROUGH GREAT MODIFICATIONS IN THE LAST DECADES. IN BRAZIL, ESPECIALLY AFTER 1988 FEDERAL CONSTITUTION, IT IS VERIFIED AN IMPORTANT INCREASE IN THE JUDICIALIZATION OF SOCIAL RELATIONS AND POLITICS, AND, CONSEQUENTLY, IN THE IMPORTANCE OF THE JUSTICE ADMINISTRATION. BESIDES, THE JUDICIAL FUNCTION HAS NOWADAYS A RELEVANT RELATION WITH THE ADMINISTRATIVE FUNCTIONS OF THE COURTS. THEREFORE, A SATISFACTORY JURISDICTIONAL INSTALLMENT REQUIRES ALSO GOOD ADMINISTRATIVE PRACTICES. IN THIS SENSE, THE NUMBER OF STUDIES ABOUT GOOD GOVERNANCE CONCEPTS AND TECHNIQUES IN THE PUBLIC SUBJECTS IS PROGRESSIVELY INCREASING. IN THIS PAPER, IT IS BACKED THAT THE NEW COMPREHENSION OF THE JUSTICE MODEL NECESSITATES GOOD GOVERNANCE TECHNIQUES AND PRACTICES IMPLEMENTATION IN THE COURTS, LEADED BY THE NATIONAL JUSTICE COUNCIL, MAINLY THE ONES RELATED WITH THE TRANSPARENCY, PARTICIPATION, EFFICACY, EFFICIENCY AND COHERENCY IDEAS.

\section{KEYWORDS}

National Justice Council; Justice functions; Justice ADMINISTRATION; GOOD GOVERNANCE; PRINCIPLES.

\section{INTRODUÇÃO}

O Conselho Nacional de Justiça desempenha um papel central dentro do sistema judiciário brasileiro. Suas decisões refletem-se diretamente sobre os atos e políticas públicas do Poder Judiciário - e, em consequência, na vida dos cidadãos. Embora a função típica dos tribunais seja a jurisdicional, eles também desempenham relevantes funções administrativas, ou seja, servidores, juízes, desembargadores e ministros 
empregam grande parte do seu tempo de trabalho em questões administrativas, principalmente quanto à condução dos processos judiciais, a divisão do trabalho entre seus membros e a divisão estrutural e material dos seus recursos. Assim, existe uma estreita ligação entre as funções judiciais e administrativas, que necessitam, portanto, de uma coordenação para êxito da prestação jurisdicional. A Emenda Constitucional n. 45/2004, atenta a considerações dessa ordem, criou o CNJ com o objetivo primaz de centralizar e organizar a administração do Judiciário brasileiro.

De outro lado, as sociedades contemporâneas não conseguem responder satisfatoriamente ao conjunto cada vez mais complexo e crescente de demandas oriundas ou constituídas no sistema social, em face da impossibilidade de gerar um conjunto unitário de respostas dotadas de racionalidade e coerência (CANOTILHO, 2003, p. 1348). A dinâmica social empreende forças a outros órgãos e instituições públicas ou da sociedade civil, que, ao lado do Estado, podem atender às expectativas dos cidadãos. As novas formas de condução responsável dos assuntos públicos e do judiciário (good governance), antes restritas exclusivamente à esfera estatal, são cada vez mais compartilhadas e integradas no âmbito de atuação do Poder Judiciário, além de serem precipuamente capitaneadas pelo CNJ, órgão responsável pela coordenação administrativa, financeira e fiscalizatória do Poder Judiciário nacional.

O conceito de good governance apresenta uma arquitetura complexa (KOENIGARCHIBUGI, 2005, p. 60-63) e de relativa indefinição (GIESEN, 2004, p. 8). A expressão good governance é traduzida, em regra, como "boa governação" (Tratado Constitucional da União Europeia - Tratado de Nice), ou "boa governança" (Livro Branco da Comissão Europeia sobre governança europeia (COM. (428) final, de 25 de julho de 2001). De acordo com Aragão, a melhor tradução seria "boa governância". A opção por "governância” está na linha de vocábulos de origem latina que em português mantêm a terminação "ância”, que exprime a ideia de ação ou resultado de uma ação (ARAGÃO, 2005, p. 105-107.)

As características comuns desse conceito são o incremento da aplicação de diversas técnicas de gestão e de formas indiretas (regulações) de condução dos assuntos públicos, além da participação de atores públicos e privados e da combinação de níveis institucionais (global, regional, nacional, local) (SAND, 2004, p. 44). A proposta visa transformar os princípios clássicos com métodos modernos de gestão e pauta-se pela abertura para a participação do maior número de atores na tomada de decisões, pelo combate à opacidade e à inoperatividade das organizações de poder e, ainda, pela responsabilização, transparência e coerência, sem esquecer-se das eventuais e possíveis consequências das atuais decisões para as gerações futuras (ROSENAU, 2005, p. 71-73; LAKE. KAHLER, 2003, p. 3-15; MAYNTZ, 1999, p. 4). Gomes Canotilho explicita a importância do tema à medida que concebe a good governance dos recursos públicos como um dos mais importantes instrumentos de "optimização (sic) dos direitos sociais" (CANOTILHO, 2008-B, p. 249). 
A boa governância requer modos de unir as esferas da vida (política, científica, econômica, jurídica) por diferentes redes de conexão e interação, mantendo ainda sua autonomia social. Há, ainda, um imenso vácuo na sociedade entre os espaços não ocupados ou subocupados e os cidadãos, principalmente quanto às questões de igualdade de gênero, direitos humanos, direitos ambientais e minorias, que precisam ser debatidas pelo Poder Judiciário ou atendidas pela participação da sociedade civil. Novos atores não estatais ou supranacionais muitas vezes estão mais próximos da situação e têm preenchido as lacunas com respostas que proporcionam contentamento, ganhando destaque no cenário da prevenção, pacificação e resolução de conflitos. A cooperação e a interação dialógica entre a rede de novos atores na direção dos assuntos antes reservados ao Poder Judiciário representam a nova forma de direção - a good governance (WOODS, 2005, p. 26-29).

A adoção das ideias de boa governância no âmbito do CNJ é acelerada pela perda de confiança e credibilidade do Poder Judiciário junto à sociedade, e reforçada pela concepção de que o sistema de resolução dos conflitos não pode ser exclusivo do Estado (BOGASON; MUSSO, 2006, p. 5). São diversos os motivos que desencadearam esse processo: a falta de eficácia e de eficiência dos sistemas de direção estatal (judiciário), a aparente inefetividade das decisões judiciais, a sobrecarga do Estado, a perpetuação de processos ortodoxos (rotinas redundantes) e o distanciamento dos órgãos judiciários em relação à sociedade (CANOTILHO, 2003, p. 1348).

Contudo, o Poder Judiciário ainda é relevante e necessário para o sistema estatal, e o CNJ é um órgão indispensável para a ligação dos diversos órgãos jurisdicionais que integram o sistema judicial brasileiro. Assim, na rede de interações e nos múltiplos níveis de constitucionalismo, o Poder Judiciário também tem como objetivo coordenar e interagir com as demais esferas de resolução de conflito. Dessa forma, o monopólio sobre a legitimidade do poder precisa ser compartilhado com outras autoridades legitimadas que contribuam para a segurança da ordem e a pacificação e prevenção dos conflitos, além de participarem da regulação econômica e social (SENARCLENS, 1998, p. 199-201).

As respostas e soluções às indagações não são simples. O presente texto não pretende esgotar o tema, mas trazer contributos para o aprimoramento e a excelência da prestação jurisdicional, no que respeita à atuação do Conselho Nacional de Justiça sob a perspectiva das recentes formas de condução dos assuntos públicos, ou seja, das novas práticas e técnicas da chamada good governance.

Para tanto, em um primeiro momento esclarecem-se e relembram-se questões importantes atinentes ao CNJ para, depois de aclaradas em breves linhas as suas duas funções, dedicar atenção maior aos princípios da good governance e ao modo como eles podem ser (e, conforme o caso, já estão sendo) aplicados por referido órgão em sua função administrativa. O artigo, portanto, busca realizar tarefa tão difícil quanto importante, qual seja, lançar sólidos fundamentos teóricos para, a 
partir deles, unir a teoria à prática e constatar quais as áreas em que ambas podem integrar-se harmonicamente.

\section{i Conselho Nacional de Justiça:}

COMPOSIÇÃO E ATRIBUIÇÕES DOS CONSELHEIROS

O Conselho Nacional de Justiça foi instituído pela Emenda Constitucional n. 45, de 30 de dezembro de 2004, mediante a inclusão do artigo 103-B na Constituição da República. Trata-se de órgão do Poder Judiciário encarregado de supervisionar a atuação administrativa dos órgãos desse Poder e a dos juízes, no que tange ao cumprimento de seus deveres funcionais.

A composição do CNJ é definida pela Constituição Federal. Gilson Dipp esclarece, acerca da função de Presidente, que o CNJ é presidido pelo Ministro Presidente do Supremo Tribunal Federal, que só votará em caso de empate e não recebe distribuição "naquele Tribunal, embora as estruturas administrativas respectivas, sobretudo no que pertine à Corregedoria Nacional, não guardem paralelo com as finalidades da Corte Suprema" (DIPP, 2009, p. 30).

As atribuições dos Conselheiros nos termos dos artigos 17 e 18 do Regimento Interno do órgão são: a elaboração de projetos, propostas ou estudos sobre matérias de competência do CNJ; o requisito junto a quaisquer órgãos do Poder Judiciário, do $\mathrm{CNJ}$ e de outras autoridades competentes das informações e meios que considerem úteis para o exercício de suas funções; a propositura à Presidência da constituição de grupos de trabalho ou Comissões necessários à elaboração de estudos, propostas e projetos a serem apresentados ao Plenário do $\mathrm{CNJ}$; a propositura de convocação de técnicos, especialistas, representantes de entidades ou autoridades para prestar os esclarecimentos que o CNJ entenda convenientes; o pedido de vista dos autos de processos em julgamento e o desempenho das funções de Relator nos processos que lhes forem distribuídos.

\section{As funções do Conselho Nacional de Justiça}

\section{I FisCALIZATÓRIA}

Consoante se esclareceu anteriormente, o presente artigo tem como objeto precípuo de estudo a aplicação dos princípios da good governance ao Conselho Nacional de Justiça, com ênfase na sua função administrativa. Portanto, não se dedicará igual atenção à função fiscalizatória, já que tal implicaria em um indesejado desvio de rota.

Todavia, algumas palavras devem ser dispensadas ao tema, já que a responsabilidade dos integrantes do poder judiciário é um importante tema no debate atual (GARAPON, 
2003, p. 20). A principal questão é saber para quem presta contas da sua atividade um membro do poder judiciário, e como e quando os tribunais podem fornecer mais responsabilidade institucional (GRABER, 2003, p. 35). Os membros de qualquer empresa ou entidade são avaliados por seus atos, que repercutem em benefícios ou perdas dentro do campo de trabalho; a classe política é avaliada nas eleições. Geralmente, o poder judiciário não apresenta mecanismos efetivos de avaliação e de responsabilização dos seus membros. O levantamento de dados estatísticos não é suficiente. As corregedorias desempenham um importante papel no que respeita ao controle disciplinar e administrativo; todavia, esse trata-se de um controle mais repressivo do que preventivo, ou seja, os juízes e ministros não são submetidos a processos contínuos de avaliação interna.

A questão aqui tratada ultrapassa a responsabilidade civil, penal e administrativa, inerente a qualquer pessoa integrante de um cargo público. A autonomia administrativa e financeira dos tribunais (artigo 99 da Constituição) não os exime de prestarem as suas contas perante os Tribunais de Contas. A criação do Conselho Nacional de Justiça e do Conselho Nacional do Ministério Público, pela Emenda Constitucional n. 45/04, representou um importante avanço para o controle das atividades do Poder Judiciário (COSTA, 2006, p. 78). Contudo, esses mecanismos constitucionais não englobam nenhuma outra forma expressa de avaliação e responsabilização dos membros do judiciário. Atualmente, a avaliação, para além das atividades das corregedorias dos tribunais, restringe-se a uma responsabilidade pessoal, ou seja, relaciona-se com a consciência de cada juiz ou ministro no e pelo exercício de sua atividade. O juiz institucionalmente responsável cumpre as suas obrigações específicas de caráter individual e assume um compromisso ativo no bom funcionamento de todo o sistema judicial.

A good governance implica na implantação efetiva do princípio da responsabilização e pode ajudar a responder a essa questão. É imprescindível criar mecanismos de avaliação permanente e periódica das atividades administrativas para diagnosticar as mazelas e exercer melhor o controle, além de verificar a eficiência da prestação dos serviços judiciais. A participação da sociedade civil é relevante para o sucesso da avaliação e da responsabilização, pois implica sintonia profunda entre as medidas adotadas pelo judiciário e as aspirações dos cidadãos.

\subsection{Administrativa}

O artigo 103-B, $\S 4^{\circ}$, da Constituição Federal, incluído pela Emenda Constitucional n. 45, atribuiu ao Conselho Nacional de Justiça competência para o controle da atuação administrativa e financeira do Poder Judiciário. Com efeito, uma das principais atribuições do CNJ é de índole administrativa, na medida em que cabe a ele organizar e controlar os atos administrativos da Justiça. Uma das formas de exercício dessa competência radica na edição de resoluções com a finalidade de organizar o Poder 
Judiciário. Exemplo disso é a Resolução n. 7, de 18 de outubro de 2005, que veda a prática do nepotismo em todos os órgãos do Poder Judiciário.

Além disso, incumbe ao Conselho Nacional de Justiça, relativamente à sua função de caráter administrativo, concretizar os princípios elencados no artigo 37 da Constituição, quais sejam, legalidade, impessoalidade, moralidade, publicidade e eficiência, conforme dispõe o artigo 103-B, § 4 , II, da Constituição Federal (BAGATINI; WICKERT, 2010, p. 161). Sobre o papel administrativo do CNJ seguirá a abordagem do presente texto.

\section{Princípios de good governance e Práticas do poder JUdiciário}

Gomes Canotilho propugna que a good governance significa, em uma compreensão normativa, a condução responsável dos assuntos do Estado em todas as esferas: governo/administração, legislativo e judiciário. Acentua-se a interdependência internacional dos Estados, considerando-se as questões de governo problema de multilateralismo dos Estados e de regulações internacionais. Recuperam-se ainda algumas dimensões do gerenciamento público e insiste-se em questões politicamente fortes como as da governabilidade, da responsabilidade e da legitimação (CANOTILHO, 2006-A, p. 327).

$\mathrm{Na}$ ótica do Banco Mundial, por outro lado, a good governance engloba quatro áreas chaves de ação: gestão eficiente do setor público; accountability da ação estatal e administrativa; transparência e disponibilização ativa de informação; e, por fim, um sistema jurídico confiável (WORD BANK, 1992). Nessa senda, Jayme Weingartner Neto e Vinícius Diniz Vizzotto aclaram que a good governance consiste em um conceito que ganha relevo na década de 1990, na esfera do desenvolvimento econômico e político, claramente relacionado ao Consenso de Washington. Atualmente o conceito é estudado em diversas ciências e aplicado tanto a pessoas jurídicas privadas como públicas. Lembram, ainda, que o Acordo de Cotonou, no artigo $9^{\circ}$, define "boa governança" como a "gestão transparente e responsável dos recursos humanos, naturais, econômicos e financeiros para efeitos de desenvolvimento equitativo e sustentável" (WEINGARTNER NETO e VIZZOTTO, 2008, p. 287).

A good governance, a par da difusão do conceito, traduz-se em uma série de princípios constitutivos, que surgem, conforme Canotilho, como totalidades modeladoras e transempíricas, implicadoras de integração de argumentos constitucionais, ligados à autoridade do direito posto e de argumentos substantivos ou prático-gerais, cuja força repousa no conteúdo (CANOTILHO, 2006-B, p. 10). Os aprimoramentos da função judicial passam pela adoção de boas práticas correlacionadas aos princípios que informam a boa governância, ou seja, transparência, responsabilidade, eficácia, eficiência, participação e coerência. 


\section{I TRANSPARÊNCIA}

Entre as principais aspirações da sociedade civil organizada estão o acesso à informação e a livre expressão. O interesse consiste em conhecer, acompanhar e refletir sobre os atos privados e da administração pública, inclusive do judiciário.

Os meios de comunicação têm um papel fundamental no acesso à informação, que é facilitada pelas novas tecnologias (NUTLEY; BOAZ, 2003, p. 31). A função da imprensa de informar, quando exercida com seriedade, profissionalismo e de maneira imparcial, constitui fundamental mecanismo de controle social das instituições, além de contribuir para a aproximação do judiciário com a sociedade. Além disso, os novos meios tecnológicos auxiliam na prossecução da transparência: tem-se, por exemplo, a internet como importante mecanismo de transparência pela facilidade e rapidez do processamento dos dados, além do rádio e da televisão, valendo ressaltar que o Brasil é o único país que transmite pela rádio e televisão, ao vivo, todas as sessões do STF.

Contudo, para além do desenvolvimento tecnológico como ferramenta de aumento do poder dos cidadãos mediante o acesso à informação e ao conhecimento, existem outros mecanismos pelos quais são criadas condições de um ampliado acompanhamento e controle das políticas públicas, quer em sua concepção, implemento ou avaliação póstuma. Entre eles encontram destaque o conceito alargado de direitos relacionados à cidadania (MARSHALL; BOTTOMORE, 1992, p. 57), por um lado, assim como a própria função estatal na efetivação desses direitos, por outro (MOZZICAFREDDO, 2000, p. 35).

A publicidade e a fundamentação dos atos são maneiras eficientes de evitar a arbitrariedade. Por isso, as decisões judiciais devem ser fundamentadas e publicadas no Diário Oficial - atualmente, sobretudo em Diário Oficial Eletrônico. A partir da Emenda Constitucional n. 45/04, as decisões administrativas dos tribunais também são motivadas e deliberadas em sessão pública. Contudo, a mera publicidade e fundamentação dos atos já não são suficientes.

A transparência, nessa esteira, é um adicional relativamente à publicidade. Importa na demonstração ampla de todos os atos relacionados ao bom desempenho da gestão dos tribunais, não se restringindo à fundamentação e a publicidade do ato. A transparência implica na organização completa de dados e informações sobre o que acontece nos tribunais. A comunicação contínua e direta dos trabalhos desenvolvidos pelo judiciário facilita o acesso de um maior número de pessoas e promove a verificação e a discussão sobre as atividades judiciais. A transparência poderá clarificar questões importantes sobre o modo e a forma como trabalham os integrantes do judiciário, o processo de deliberação e as interações com a sociedade, além de outras questões muitas vezes obscuras como a assiduidade, produtividade, eficiência, desempenho, capacitação e experiências multidisciplinares.

A acessibilidade das informações contribui, assim, para o aperfeiçoamento do sistema judicial, além de facilitar o trabalho dos profissionais da área jurídica. Desse 
modo, o CNJ tem como uma de suas funções primordiais a ampla divulgação à sociedade civil dos atos dos tribunais e dos juízes, salvo aqueles que sejam imprescindíveis à segurança da sociedade, do Estado e à intimidade dos particulares.

A transparência, igualmente, pode combater questões pontuais do judiciário, principalmente quanto aos chamados processos "engavetados", ou seja, processos que por diversos motivos têm duração mais longa do que a média normal. O máximo de segredo acaba por facilitar a corrupção (CANOTILHO, 2006-A, p. 129), mas quanto maior a transparência, tendencialmente menor é a probabilidade de corrupção - é dizer, a transparência é o outro lado do problema da corrupção (CANOTILHO, 2008-A, p. 19-20).

Além disso, com a implantação efetiva da transparência talvez seja possível esclarecer ou encontrar pistas sobre o mito da morosidade e da lentidão que envolvem o poder judiciário. No plano supranacional, a transparência das informações pode levar ao conhecimento de diferentes práticas adotadas em lugares com peculiaridades não difundidas em outros países (KISKIS; PETRAUSKAS, 2004, p. 20).

No que respeita à transparência na condução dos assuntos públicos, deve-se dispensar algumas palavras à designada “Lei de Acesso à Informação” (Lei 12.527/2011). Regula essa Lei o exercício do direito de acesso à informação previsto no artigo $5^{\circ}$, inciso XXXIII, no artigo 37, inciso II, $\S 3^{\circ}$ e no artigo $216, \S 2^{\circ}$, todos da Constituição da República. Disciplina, portanto, conforme dispõe no artigo $1^{\circ}$, os procedimentos a serem observados pela União, Estados, Distrito Federal e Municípios, com o fim de garantir o acesso a informações previsto nos precitados dispositivos. Trata-se, indubitavelmente, de instrumento normativo valioso à implementação do princípio da transparência no âmbito do Poder Judiciário, de modo geral, e no Conselho Nacional de Justiça, de modo específico.

O Conselho Nacional de Justiça realiza uma série de programas com vistas a promover e intensificar a transparência relativamente aos assuntos da administração da Justiça e da prestação jurisdicional. Especial destaque deve ser dado ao programa “Justiça Plena”, lançado em 2010 pela Corregedoria Nacional de Justiça. A iniciativa tem por escopo monitorar e ampliar a transparência de processos com grande repercussão social. São causas em que se discutem importantes temas criminais, consumeristas e ambientais, além de ações civis públicas e ações populares de alto interesse público. Trata-se de programa exemplar no que diz com a coerência de ações voltadas a um objetivo comum, na medida em que, entre coordenadores e participantes, o "Justiça Plena" envolve oito protagonistas: o Ministério da Justiça (MJ), o Conselho Nacional de Justiça (CNJ), a Advocacia- Geral da União (AGU), a Secretaria de Direitos Humanos (SDH), o Conselho Nacional do Ministério Público (CNMP), a Ordem dos Advogados do Brasil (OAB), a Defensoria Pública da União e dos Estados e a Procuradoria Federal dos Direitos do Cidadão (PFDC).

Outro sistema desenvolvido pelo CNJ na perspectiva do princípio da transparência é o chamado "Justiça Aberta". Consiste em um sistema de consulta com objetivo 
de simplificar o acesso dos jurisdicionados a informações acerca da localização de varas cíveis, tribunais, cartórios e outras instituições a serviço do sistema judiciário nacional, bem como sobre relatórios de produtividade das secretarias processuais. $\mathrm{O}$ sistema opera com um banco de dados gerenciado pela Corregedoria Nacional de Justiça; por meio dos menus disponibilizados no sistema, é possível ter acesso aos dados quantitativos sobre atos recebidos e deliberados nas secretarias das varas cíveis, em primeira instância, assim como acessar os dados quantitativos sobre votos, encaminhamentos e outras decisões de juízes, desembargadores e corregedores, em segunda instância. Além disso, são disponibilizados, no item relativo às serventias judiciais, os dados sobre a produtividade dos cartórios, subdistritos e ofícios de notas, protestos e registros, que reconhecem, atestam e certificam atos particulares e públicos, como nascimentos, óbitos, imóveis, notas e processos jurídicos.

Base de dados altamente relevante, no mesmo sentido, é a designada "Justiça em Números”. As informações sistematizadas e disponibilizadas pelo sistema permitem a formação de um panorama geral do Poder Judiciário, com fulcro em dados apresentados pelos tribunais a respeito de processos distribuídos e processos julgados, número de cargos de juízes ocupados e número de habitantes atendidos por juiz. A pesquisa, assim realizada, possibilita a avaliação dos tribunais quanto à quantidade de processos, além de demonstrar o perfil de cada região e Unidade Federativa. O programa ainda tem por finalidade fazer que os dados constituam parâmetro para o desenvolvimento de uma cultura de planejamento e gestão estratégica também no âmbito da administração da Justiça. O estudo também propicia a construção de políticas de gestão e a análise da necessidade de criação de cargos e funções. As informações quantitativamente explicitam, de igual modo, despesas com pessoal, recolhimentos e receitas, informática, taxa de congestionamento e carga de trabalho dos juízes.

Finalmente, um instrumento mais conhecido e não menos importante que pode ser mencionado é o "Portal da Transparência” pertinente ao Poder Judiciário, ferramenta que concretiza o princípio da transparência da gestão fiscal e leva a conhecimento e acompanhamento da sociedade, mediante qualquer pessoa física ou jurídica, dados relativos à execução orçamentária e financeira do Poder Judiciário.

\subsection{Participação}

No âmbito do CNJ é cada vez mais difundida a participação dos integrantes da sociedade nas atividades de repercussão social ou econômica. A possibilidade de intervenção de qualquer pessoa nos processos administrativos, com a finalidade de esclarecer, subsidiar e informar sobre as questões relacionadas ao Poder Judiciário apresenta um forte conteúdo de participação política e democrática na tomada de decisões sobre assuntos relevantes para a administração da Justiça. Isso porque o Estado, para além da clássica concepção weberiana, não se limita a um território definido, com monopólio e uso legítimo da força, mas "processa e condensa poderes 
que emergem da sociedade (em nível local, internacional e transnacional)" (O’DONNELL, 2011, p. 68).

Tem-se, portanto, uma concepção democrática que transcende em muito a mera representação, não se restringindo ao mecanismo do voto. A qualidade, a pertinência e a eficácia dos processos decisórios públicos necessitam de ampla participação em todo o processo político. Dependem principalmente da utilização e do incentivo, por parte da administração central, de uma abordagem aberta e abrangente. A democracia participativa, assim, representa um importante mecanismo para a interação entre o político e o social (SANTOS, 2003, p. 77; SANTOS, 2002, p. 50, BOCHENEK, 2013).

A participação da sociedade civil nos assuntos relativos ao sistema judicial é extremamente relevante, porquanto é ela a destinatária final da prestação jurisdicional. O processo de decisões administrativas no âmbito dos tribunais deve contar também com a participação de magistrados de primeiro grau e dos cidadãos.

No que respeita de forma específica ao Conselho Nacional de Justiça, certos dados podem demonstrar a importância de práticas de ampliação da participação, bem como o modo pelo qual algumas delas têm sido impostas ou implementadas.

Primeiramente, a própria composição do órgão revela a atenção que o constituinte derivado dedicou à questão, já que, nos termos do artigo 103-B, inciso XIII, da Constituição Federal, dois membros do CNJ serão “cidadãos, de notável saber jurídico e reputação ilibada, indicados um pela Câmara dos Deputados e outro pelo Senado Federal”. Significa dizer: a sociedade civil vê-se representada na composição do Conselho Nacional de Justiça, por expressa previsão constitucional, valendo ressaltar, ademais, que um dos membros será indicado pela Câmara dos Deputados, órgão que "compõe-se de representantes do povo" (artigo 45 da Constituição), e outro pelo Senado Federal, composto por "representantes dos Estados e do Distrito Federal" (artigo 46 da Constituição). Em outras palavras, têm-se os órgãos que integram o Congresso Nacional, representativos do povo e dos Estados e Distrito Federal, a indicar dois cidadãos como membros do Conselho Nacional de Justiça.

Impende observar, ainda, que não só o inciso XIII revela a preocupação constitucional com uma composição que concretizasse, em relação ao CNJ, o princípio da participação - e também nem se restringe a ela. É notável, nesse sentido, como o órgão é composto por representantes dos diversos segmentos do Poder Judiciário (Supremo Tribunal Federal, Superior Tribunal de Justiça, Tribunal Superior do Trabalho, Tribunais de Justiça, juízes estaduais, Tribunais Regionais Federais, juízes federais, Desembargadores da Justiça do Trabalho, juízes do trabalho), além do Ministério Público da União, do Ministério Público estadual e advogados.

Na mesma senda, as Comissões do Conselho Nacional de Justiça têm, entre suas atribuições, conforme estabelecido pelo artigo 28, incisos II e III do Regimento Interno, "realizar audiências públicas com órgãos públicos, entidades da sociedade civil ou especialistas" e "receber requerimentos e sugestões de qualquer pessoa sobre tema 
em estudo ou debate em seu âmbito de atuação", isto é, duas atribuições que levam a efeito diretamente o princípio da participação da sociedade civil na tomada de decisões relativas à administração do Poder Judiciário. Além disso, dispõe o $\S 2^{\circ}$ do artigo 28 que "nas Comissões buscar-se-á a participação proporcional, preservando, sempre que possível, a representação das diversas categorias funcionais”, e que, em sua composição, haverá ao menos um Conselheiro não integrante da magistratura.

É possível, ainda, a qualquer pessoa com interesse legítimo - além do Ministério Público, Presidentes dos Tribunais e, de ofício, Conselheiros - representar contra magistrado por excesso injustificado de prazo, para a prática de ato de sua competência jurisdicional ou administrativa, nos termos do artigo 78 do Regimento Interno. Embora se trate de ato de caráter também fiscalizatório, vê-se nessa hipótese evidente abertura à participação de jurisdicionados nas atividades do CNJ.

O Regimento Interno do Conselho Nacional de Justiça prevê igualmente, no artigo $4^{\circ}$, inciso XII, a participação dos órgãos do Poder Judiciário, podendo para tanto serem ouvidas as associações nacionais de classe das carreiras jurídicas e de servidores, em sessão plenária de planejamento especialmente convocada para definição do planejamento estratégico, dos planos de metas e programas de avaliação institucional do Poder Judiciário.

O CNJ realiza, nessa linha, por meio da Corregedoria Nacional de Justiça, audiências públicas nos tribunais a fim de ouvir as críticas, sugestões e propostas da comunidade local. Nesses atos, colhe reclamações, notícias e observações tendo em vista o aprimoramento da prestação jurisdicional na localidade ouvida. Entre janeiro de 2009 e junho de 2011, por exemplo, foram promovidas audiências públicas em onze estados brasileiros, com reiteradas participações de entidades relacionadas às atividades jurisdicionais e centenas de solicitações e reclamações dirigidas por cidadãos.

Ranson e Stewart sublinham a importância de processos consultivos, a exemplo das audiências públicas, enquanto medida que permite o balanceamento do papel do governo representativo e do papel da participação do cidadão nos processos de tomada de decisão. Mas isso na medida em que políticas que fomentam a cidadania ativa não deflagram efeitos de modo rápido, exigindo um tempo até que os resultados possam ser verificados. Assim, os autores mencionam algumas medidas que permitem temperar as realidades da representação política e da participação dos cidadãos. Além dos processos consultivos (inquéritos, workshops, seminários, referendos e, como dito, audiências públicas), elencam a dispensa de maior atenção aos protestos públicos, pressões, debates e reclamações dos cidadãos; o desafio do governo mediante petições; e a participação ativa por meio de comitês e associações (RANSON; STEWART, 1989, p. 10).

\section{$3 \cdot 3$ Coerência}

Existe atualmente uma clara "crise de reflexibilidade", conforme preconiza Canotilho, na qual se exprime "a impossibilidade de o sistema regulatório central 
gerar um conjunto unitário de respostas dotadas de racionalidade e coerência relativamente ao conjunto cada vez mais complexo e crescente de demandas ou exigências oriundas do ou constituídas no sistema social” (CANOTILHO, 2003, p. 1348).

Em termos gerais, sob a ótica jurídico-política, o princípio da coerência relacionase com a articulação sistemática entre o ato em causa e todo o sistema político-jurídico (ARAGÃO, 2005, p. 127). Desse modo, a conceituação da coerência deve observar as matizes de padrão de cada setor (público e privado), área (política, social, econômica, cultural) e lugar (local, regional, nacional ou global).

A incoerência das ações consiste tradicionalmente em elemento essencial do declínio de confiança dos cidadãos no setor público. Diversas atividades e serviços públicos são redundantes, ociosos e desperdiçados, ao passo que os furos da rede de segurança social permanecem descobertos. A incoerência acarreta maiores despesas, onerosidade e ineficiência na consecução dos objetivos públicos. Crises, riscos, falhas e reestruturações da rede de governância são bastante comuns (ROTHSTEIN, 2006, p. 215-217).

Nessa senda, a good governance pode apresentar novas opções e caminhos para os sistemas judiciais, que são cada vez mais complexos, diversificados e híbridos. As esferas de poder social organizatório transcendem ao poder judiciário estatal oficial e necessitam ser coordenadas e integradas por meio de ações coesas e interligadas. Governance, nesse sentido, designa também o modelo de relacionamento entre os diversos atores sociais, cada qual em seus específicos recursos de poder, que se estabelece pautado em regras e procedimentos institucionalizados (COPEDGE, 1995, p. 24).

Os atores principais (tribunais) não são os únicos, mas são imprescindíveis para iniciar e irradiar para a sociedade e os cidadãos as transformações necessárias de todo o aparato do sistema de justiça. Para tanto, é necessário coerência entre as medidas para a promoção de ações de alta intensidade com o objetivo ideal de ligação entre os atores (estatais e da sociedade civil) que participam da rede de sistemas de resolução de conflitos (GIESEN, 2004, p. 5-7). Nesse sentido, uma cidadania ativa, na medida em que congrega a contribuição de um heterogêneo conjunto de atores e interesses, contribui para o alcance de resultados mais satisfatórios na administração das organizações públicas (CALLAHAN, 2007, p. 30).

O grande desafio do CNJ e de todo o sistema judicial brasileiro, em termos de coerência, é realizar a unificação administrativa e organizacional do sistema judicial (justiça eleitoral, militar, do trabalho, federal e estadual) e promover harmonicamente a inserção das demais formas de resolução de conflitos, sem descurar da convivência harmônica com os meios alternativos de resolução de conflitos. A divisão de trabalho entre os juízes e servidores revela-se importante para a organização dos serviços, mas atualmente carece de integração administrativa e jurisdicional, e principalmente de coerência. As boas práticas precisam ser enaltecidas e implantadas em prol de objetivos comuns e da excelência da prestação jurisdicional. 
A informatização dos sistemas judiciais é um tema em destaque. Com efeito, diversos estudos demonstram atualmente o poder das adventícias Tecnologias da Informação e Comunicação - TICs sobretudo na internet, como forma de oportunizar a participação dos cidadãos na condução dos negócios públicos e, assim, aperfeiçoar o sistema democrático. Chahin, nesse sentido, aduz que "a telemática a união das tecnologias de informação e de comunicação eletrônicas digitais e convergentes - oferece meios poderosos e cada vez mais baratos de aperfeiçoar nossa democracia, pagar nossa dívida social e estimular nossa economia" (CHAHIN, CUNHA, et al. 2004, p. 3.)

No âmbito judicial, cada tribunal, ao seu ritmo, tem elaborado programas de tramitação virtual de processos que são utilizados em primeira e segunda instância. Contudo, esses processos judiciais eletrônicos podem chegar aos tribunais superiores. Então, deve-se perguntar o que é mais racional, lógico, prático e econômico: o STF possuir os diversos programas de informática de cada tribunal para processar os recursos ou desenvolver-se um programa que possa ser utilizado por todas as instâncias e esferas do poder judiciário? A resposta parece óbvia. O CNJ instaurou, nessa esteira, o chamado "Processo Judicial Eletrônico" (PJe), programa informático desenvolvido em parceria com os tribunais com o objetivo de automação da Justiça. A iniciativa congrega, mesmo que carregada de críticas, uma ampla série de órgãos judiciais e envolve, ainda, o trabalho de diversos técnicos de informática para a instalação dos softwares. $\mathrm{O}$ sistema visa implantar a ideia do processo judicial eletrônico unificado, pelo qual seja possível a prática de atos processuais pelos magistrados, servidores e demais participantes do processo diretamente no sistema, bem como o acompanhamento do processo, independentemente de tramitar na Justiça Federal, na Justiça dos Estados, na Justiça Militar dos Estados ou na Justiça do Trabalho.

O Conselho Nacional de Justiça tem assumido a responsabilidade de organizar certas questões importantes da área administrativa. O Conselho da Justiça Federal, por sua vez, é responsável somente pela administração da justiça federal. Dessarte faz-se necessário e urgente o desenvolvimento de uma estrutura administrativa que possa coordenar e integrar de forma coerente toda a administração da justiça brasileira, além de interagir e promover os meios alternativos de resolução de conflitos, na medida em que a integração é um ponto essencial para o sucesso da concretização do princípio da coerência (YALL; TAIT, 2005, p. 7).

No âmbito específico do Conselho Nacional de Justiça são desenvolvidos alguns programas de informática em parceria com outros órgãos, com o objetivo de promoção do acesso à informação e minoração da burocracia tão comum nos atos processuais.

Exemplo de sistema unificado na esfera judicial e que na maior parte das vezes e se utilizado de forma correta e sem distorções, evidentemente - traz benefícios à prestação jurisdicional é o "BacenJud", sistema que interliga às instituições financeiras e ao Banco Central o Poder Judiciário, no intuito de tornar mais célere a requisição de 
informações e a expedição de ordens judiciais ao Sistema Financeiro Nacional. Tratase de iniciativa realizada mediante convênio entre o Poder Judiciário e o Banco Central do Brasil, que opera o sistema a partir de convênio firmado com o Conselho Nacional de Justiça.

Pode ser citado, igualmente, o chamado "Sistema BNMP" - Banco Nacional de Mandados de Prisão, cujas finalidades consistem em: a) possibilitar o conhecimento, por qualquer pessoa, dos mandados de prisão com a situação "aguardando cumprimento", desde que ainda vigentes; e b) facilitar o cumprimento de diligências pelas autoridades policiais, bem como auxiliar os juízes a exercer a sua jurisdição, na medida em que disponibiliza, por meio de autenticação do usuário do sistema, o acesso a todos os mandados de prisão, independentemente de sua situação ou da data de validade. Em sentido semelhante, o Conselho Nacional de Justiça implantou o sistema "Infoseg", rede com estratégia de integração das informações de Segurança Pública, Justiça e Fiscalização, de modo a contribuir também para a atividade de inteligência nacional. A rede opera interligando as bases de informações federais e estaduais, constituindo um Banco Nacional de Índices com diversos dados acerca de inquéritos, processos, armas de fogo, veículos e condutores, mandados de prisão, entre outros, mantidos e administrados pelos Estados e órgãos conveniados; trata-se do maior sistema nacional de informações de segurança pública. Relembre-se, nessa senda, que, a fim de superar obstáculos à integração e, por consequência, à coerência (no caso, das informações de diferentes bancos de dados), a governância deve empregar todos os instrumentos de integração de que dispuser: regulação, conformidade transversal, ajuda financeira, instrumentos fiscais, treinamento e, especificamente nessa hipótese, troca de informação (DHONT, 2003, p. 463 e ss.).

Sistema importante, ainda, desenvolvido pelo Conselho Nacional de Justiça, é o assim designado "Sistema Nacional de Controle de Interceptações Telefônicas", que concentra as informações obtidas a partir das interceptações telefônicas judicialmente determinadas. $\mathrm{O}$ instrumento permite a emissão de estatísticas visando ao aperfeiçoamento e à uniformização do sistema de medidas cautelares sigilosas referentes às interceptações telefônicas, a fim de constituir instrumento de prova em investigação criminal e em instrução processual penal - e isso em todo o território nacional. A ferramenta busca conciliar a imprescindibilidade de preservação do sigilo das investigações e das informações colhidas, por um lado, assim como a eficácia da instrução processual, por outro. O CNJ sistematiza as informações obtidas, elaborando dados estatísticos sobre o assunto e, dessarte, estabelece os parâmetros da legalidade e os limites da ilegalidade. As operadoras telefônicas, para tanto, prestam eletronicamente ao $\mathrm{CNJ}$ as informações a respeito dos pedidos recebidos e das interceptações realizadas por força de solicitação judicial. Atualmente, o sistema é disciplinado e uniformizado pela Resolução n. 59, de 9 de setembro de 2008. 
Afora esses, diversos outros sistemas poderiam ser mencionados dentre os programas do Conselho Nacional de Justiça que radicam no princípio da good governance da coerência: "Renajud", "Sistema de Estatística do Poder Judiciário", "Sistema Nacional de Bens Apreendidos", "Malote Digital”. Este último tem a peculiaridade de ter sido desenvolvido originalmente pelo Tribunal de Justiça do Estado do Rio Grande do Norte (com o nome Hermes) apenas para uso interno. Foi cedido posteriormente ao CNJ, mediante convênio, e, uma vez adaptado, passou a permitir a troca de correspondências eletrônicas entre os diversos órgãos de todo o Poder Judiciário. Atualmente, o sistema substitui a remessa física de comunicações em todo o sistema judicial, implicando também em importante economia ao erário, e é regido pelo Resolução n. 100, de 24 de novembro de 2009.

\section{3•4 EFICÁCIA E EFICIÊNCIA}

As reformas da administração pública na última década visaram particularmente à eficiência do serviço público. Isso ocorreu dentro do contexto de um modelo de gestão pública que assentava nos valores eficiência, eficácia e economia, que se afirmou de forma destacada sobre outros modelos de administração (POLLIT; BOUCKAERT, 2000, p. 32).

Na perspectiva do good governance, especificamente, o princípio da eficácia representa a força governativa que emprega meios adequados para a produção do efeito desejado, ou seja, os meios pelos quais se implementa a governância devem ser adequados aos fins que se pretende alcançar. Aqui reside a necessidade de aprimoramento do Poder Judiciário, a ser comandada de modo precípuo pelo Conselho Nacional de Justiça, sobretudo em sua função administrativa.

É comum afirmar-se, atualmente, que os processos de modernização do Estado e de desenvolvimento econômico-social passam pelo melhoramento do judiciário, sobretudo no que respeita à sua eficácia e eficiência (ALESINA; GIAVAZZI, 2007, p. 141-150). Como uma variável determinante para a governância, o mercado requer regras de máxima simplicidade e de racionalidade elevada em função da prossecução de resultados. A título exemplificativo, cite-se a mencionada importância do uso das TICs pelos governos, como recurso que aumenta a eficácia dos serviços públicos, a partir da integração e conversão entre as tecnologias existentes (NEGROPONTE, 2006, p. 20 e passim).

Interessante é perceber que, dentre as atribuições cometidas ao CNJ pela Constituição Federal, está a de "zelar pela observância do art. 37”, nos termos do artigo 103-B, $\S 4^{\circ}$, inciso II da Constituição. Significa dizer que o Conselho tem como uma de suas missões constitucionais promover, dentro do sistema judicial brasileiro os princípios que regem a Administração Pública nacional em geral. Importa referir, nesse sentido, que nesse elenco principiológico foi acrescido, pela Emenda Constitucional n. 19, de 1998, o princípio da eficiência, o que permite afirmar a 
outorga constitucional ao CNJ para que concretize, no âmbito administrativo-judicial, o conteúdo que informa referido princípio, precisamente na linha do que foi sustentado anteriormente.

No escopo de cumprir essa tarefa constitucionalmente delegada, o Conselho Nacional de Justiça realiza uma série de programas destinados ao aprimoramento dos serviços judiciais e à modernização da Justiça, especialmente relacionados à tecnologia informacional e à comunicação do Poder Judiciário. Para além daqueles já anteriormente mencionados, a exemplo do "Malote Digital", que adentra a esfera do princípio da eficiência, pode ser citado agora o "Numeração Única".

O sistema foi implementado com base na Resolução n. 65, de 16 de fevereiro de 2008, considerando expressamente que a "Emenda Constitucional n. 45/2004 conferiu ao Conselho Nacional de Justiça a função de planejamento estratégico do Poder Judiciário”, e em observância à Resolução n. 12 do CNJ, de 14 de fevereiro de 2006, que "com o objetivo de melhorar a administração da justiça e a prestação jurisdicional, definiu padrões de interoperabilidade a serem utilizados no Poder Judiciário, entre eles a padronização do número dos processos”.

\section{CONCLUSÕES}

As funções realizadas pelo Conselho Nacional de Justiça extrapolam o âmbito jurisdicional/constitucional e abrangem também questões claramente administrativas. As incumbências constitucionalmente outorgadas reforçam a necessidade de implementação das modernas técnicas de gestão administrativa, das quais a good governance representa importantíssimo exemplo.

O CNJ deve estar atento às transformações políticas, sociais, culturais, ambientais e aos novos saberes. A interdisciplinariedade e a aplicação de modernos métodos de gestão nos assuntos públicos, influenciadas pelas noções de boa governância, devem ser captadas e inseridas no debate para a nova compreensão do modelo de justiça.

Em termos constitucionais, é grande o desafio do CNJ, na medida em que sua função na administração da justiça tem sensíveis repercussões na seara jurisdicional e, assim, na tutela dos direitos dos cidadãos. Desse modo, os aprimoramentos das funções da justiça desempenhadas pelo CNJ podem se refletir de imediato no desempenho de todas as esferas do poder judiciário brasileiro, principalmente no que respeita à excelência da prestação jurisdicional e à garantia dos direitos fundamentais. Assim, as ações requerem a convergência das boas práticas orientadas por transparência, participação, coerência, eficácia e eficiência.

Por um lado, é verdade que, conforme já esclarecido, diversas são as ações atualmente levadas a efeito pelo Conselho Nacional de Justiça que podem, em maior ou menor medida, ser apontadas como exemplos de concretizações dos princípios da good governance. Por outro lado, certo é também que há muito a avançar, seja em termos 
de transparência, seja também no que diz com a coerência, a participação, a eficácia e a eficiência.

: ARTIGO APROVADO (02/12/2013) : RECEBIDO EM 31/07/2013

\section{REFERÊNCIAS BIBLIOGRÁFICAS}

ALESINA, Alberto; GIAVAZZI, Francesco. O futuro da Europa: reforma ou declínio. Lisboa: Edições 70, 2007. p. 141-150.

ARAGÃO, Alexandra. A governância na Constituição Européia: uma oportunidade perdida? In: Colóquio ibérico: Constituição Européia - homenagem ao doutor Francisco Lucas Pires. Coimbra: Coimbra Editora, 2005.

BAGATINI, Júlia. WICKERT, Lisiane Beatriz. Ponderações Reflexivas Acerca do Conselho Nacional de Justiça. Revista de Processo, vol. 186, ago/2010.

BOCHENEK, Antônio César. A governância e o Princípio da Coerência: considerações preambulares. Revista de Doutrina da $4^{a}$ Região, Porto Alegre, n. 23, abr. 2008. Disponível em: <http://www.revistadoutrina.trf4.jus.br/ artigos/edicao023/Antonio_Bochenek.html>. Acesso em: 10 jul. 2013.

. A interação entre Tribunais e Democracia por meio do acesso aos direitos e a Justiça. Análises de experiências dos juizados especiais federais cíveis brasileiros. Conselho da Justiça Federal, 2013.

BOGASON, Peter; MUSSO, Juliet A. The Democratic Prospects of Network Governance. American Review of Public Administration, n. 36, 2006. p. 3-18.

BORGES, André. Governança e política educacional: a agenda recente do Banco Mundial. Revista Brasileira de Ciências Sociais, 18 (52), 2003, p. 125-138.

CALlAHAN, Kathe. Elements of Effective Governance. Measurement, Accountability and Participation. Nova York: CRC Press, 2007, p. 30.

CANOTILHO, J. J. Gomes. Brancosos e interconstitucionalidade: itinerários dos discursos sobre a historicidade constitucional. Coimbra: Almedina, 2006-A.

Direito Constitucional e teoria da Constituição. 7.ed. Coimbra: Almedina, 2003.

. O tempo curvo de uma carta (fundamental) ou direito constitucional interiorizado. Porto: Conselho

Distrital do Porto da Ordem dos Advogados, 2008-A. . Princípios: entre a sabedoria e a aprendizagem. Boletim da Faculdade de Direito de Coimbra. Vol.

LXXXII. Coimbra: Coimbra Editora, 2006-B. Estudos sobre Direitos Fundamentais. São Paulo, Revista dos Tribunais e Coimbra Editora (Co-edição), 2008-B.

CHAHIN, Ali; CUNHA, Maria Alexandra, et al. E-gov.br: A próxima revolução brasileira. São Paulo: Prentice Hall, 2004.

COPEDGE, Michael. Instituciones y gobernabilidad democrática en América Latina. Madrid: Síntesis, 1995.

COSTA, Flávio Dino de Castro. O Conselho Nacional de Justiça: competências e aspectos processuais. In: FREITAS, Vladimir Passos de; FREITAS, Dario Almeida Passos de (orgs.). Direito e administração da justiça. Curitiba: Juruá, 2006. p. 77-95.

DHONDT, Nele. Integration of environmental protection into other EC policies. Legal Theory and Practice. Groningen: Europa Law Publishing, 2003.

DIPP, Gilson. A Corregedoria Nacional de Justiça, o CNJ e a Constituição. Revista Jurídica Consulex, ano XIII, n. 310, 15 de dezembro de 2009.

DUPUY, Pierre-Marie. Droit Internacional Public. 3.ed. Paris: Dalloz, 1995.

FILHO, Ilton Norberto Robl. CONSELHO NACIONAL DE JUSTIÇA: Estado Democrático de Direito e Accountability. São Paulo: Saraiva, 2013.

GARAPON, Antoine. Les juges. Un pouvoir irresponsable? Paris: Nicolas Philippe, 2003. 
GIESEN, Klaus-Gerd. The post-national constellation: Habermas and "the second modernity". Res Public. A journal of legal and social philosophy. n. 10, 2004.

GOLDSMITH, Arthur A. Is governance reform a catalyst for development? Governance: An International Journal of Policy, Administration, and Institutions, 20 (2), 2007, pp. 165-186.

GOLDSMITH, Arthur. Institutions and Planned Socioeconomic Change: four approaches. Public Administration Review, 52 (6), 1992, pp. 582-587.

GRABER, Mark. A. The non-majority difficulty. Legislative difference to the judiciary. Studies in American Political Development, 1993.

KISKIS, Mindaugas; PETRAUSKAS, Remantas. ICT. Adoption in the Judiciary: Classifying of Judicial Information. International Review of Law Computers \& Technology. 2004. p. 18-45.

KOENIG-ARCHIBUGI, Mathias. Mapping Global Governance. In: HELD, David; McGREW, Anthony (orgs.). Governing Globalization. Power, authority and global governance. Cambridge: Polity Press, 2005.

LAKE, David A.; KAHLER, Miles. Governance in a Global Economy. Political Authority in Transition. Woodstock: Princeton University Press, 2003.

LOVELL, George. Legislative deferrals: Statutory ambiguity, judicial power, and American democracy. New York: Cambridge University Press, 2003.

MARSHALL, T. S.; BOTTOMORE, Tom. Citizenship and social class. Londres: Pluto Press, 1992.

MAYNTZ, Renate. La teoria della governance: sfide e prospettive. Rivista Italiana di Scienza Política, n. 1, 1999. MOZZICAFREDDO. J. Estado-Providência e Cidadania em Portugal. 2.ed. Oeiras: Celta, 2000.

NEGROPONTE, Nicholas. A vida digital. São Paulo: Companhia das Letras, 2006.

NUTLEY, Sandra. BOAZ, Anette. Evidence-based policy and practice. In: BOVAIRD, Tony; LOFFLER, Elke (orgs.). Public Management and Governance. London: Routledge, 2003.

OCDE. Public Sector Modernisation: Modernising Accountability and Control, Policy Brief. OECD Observer, Abril de 2005.

O’DONNELL, Guillermo. Democracia, agência e estado: teoria com intenção comparativa. São Paulo: Paz e Terra, 2011. POLLITT, C. e BOUCKAERT, Geert. Public Management Reform. A comparative analysis. Oxford: Oxford University Press, 2000.

RANSON; STEWART. Citizenship and government: the challenge for management in the public domain. Political Studies, 37, 1989 , p. 5-24.

ROSENAU, James N. Governance in a New Global Order. In: HELD, David; McGREW, Anthony (eds.). Governing Globalization. Power, authority and global governance. Cambridge: Polity Press, 2005.

ROTHSTEIN, Henry. The institutional origins of risk: A new agenda for risk research. Health, Risk \& Society, n. 8, 2006. p. 215-217.

SAND, Inger-Johanne. Polycontextuality as an alternative to constitutionalism. In: JOERGES, Christian; SAND, Inger-Johanne; TEUBNER, Gunther (eds.). Transnational Governance and Constitutionalism. Oxford and Portland Oregon: Hart Pulishing, 2004.

SANTOS, Boaventura de Sousa (Org.). Democratizar a Democracia: Os caminhos da democracia participativa. Porto: Afrontamento, 2003.

Democracia e participação: o caso dos orçamentos participativos de Porto Alegre. Porto: Afrontamento, 2002.

SENARCLENS, Pierre de. Mondialization, Souveraineté et Théories des Relations Internationales. Paris: Armand Colin. 1998 .

STIGLITZ, Joseph. Die Schatten der Globalisierung. München: Goldmann, 2004.

WEINGARTNER NETO, Jayme; VIZZOTTO, Vinícius Diniz. Ministério Público, ética, boa governança e mercados: uma pauta do desenvolvimento no contexto do direito e da economia. In: Direitos Fundamentais:

Orçamento e "Reserva do Possível". Porto Alegre: Livraria do Advogado, 2008.

WOODS, Ngaire. Global Governance and the role of institutions. In: HELD, David; McGREW, Anthony (eds.). Governing Globalization. Power, authority and global governance. Cambridge: Polity Press, 2005.

WORD BANK. Governance and development. Washington D.C.: The World Bank, 1992.

YALL, Catherine; TAIT, Joyce. New Modes of Governance. Developing an integrated policy approach to science, technology, risk and the environment. Edinburgh: Ashgate, 2005.

YAMAZAKI-HONDA, Ritsuko. Territorial Policy in OECD Countries. Planning Theory \& Practice, n. 6, 2005. p. 406-409. 
Rua Balduino Taques, n. 810 Centro - 84010-050 Ponta Grossa - PR - Brasil cesarbocheneklahotmail.com

Rua Assis Brasil, n. 707 Jardim Carvalho - 84015-380

Ponta Grossa - PR - Brasil viniciusdalazoanalayahoo.com.br

Rua Balduino Taques, n. 810 Centro - 84010-050 Ponta Grossa - PR - Brasil vinicius.rissettidyahoo.com.br

\section{Antonio César Bochenek}

Professor e Coordenador do Grupo de Pesquisas em Direito do Cescage

Professor da Escola da Magistratura Federal do Paraná Doutor em Direito, Justiça e Cidadania no século XXI PELA UNIVERSIDADE DE COIMBRA

\section{Vinicius Dalazoana}

Pós-graduando em Direito Tributário pela Fundação Getulio Vargas Pesquisador Vinculado à Academia Brasileira DE DiReito Constitucional

Vinicius Rafael Rissetti Acadêmico do Curso de Bacharelado em Direito pela Universidade Estadual de Ponta Grossa 
